\title{
J-slot EBG structure for SAR Reduction of Dual Band J-slot Textile Antenna
}

\author{
Ramesh Manikonda, Rajyalakshmi Valluri, Mallikarjuna Rao Prudhivi \\ Department of ECE, GITAM University, Visakhapatnam, India \\ Department of ECE, ANITS, Visakhapatnam, India \\ Department of ECE, Andhra University, Visakhapatnam, India
}

\begin{tabular}{l} 
Article Info \\
\hline Article history: \\
Received May 18, 2018 \\
Revised Jul 19, 2018 \\
Accepted Aug 2, 2018 \\
\hline
\end{tabular}

Keywords:

J-slot EBG

SAR

Textile antenna

WBAN

\begin{abstract}
In this article, the dual band is achieved with $\mathrm{J}$-slot on rectangular Textile antenna on Jeans fabric as substrate. It resonates at the $2.4 \mathrm{GHz}$ and $5.4 \mathrm{GHz}$ of Wireless Body Area Network (WBAN) bands. The novel J-slot Electromagnetic Band Gap (EBG) array consists of $2 \times 2$ elements. It is used as superstrate of J-slot textile antenna for Specific Absorption Rate (SAR) reduction and gain enhancement. The Reflection coefficient and VSWR of dual band textile antenna are simulated and measured with and without human body.
\end{abstract} All rights reserved.

Corresponding Author:

Ramesh Manikonda, Department of ECE, GITAM University, Visakhapatnam, India. Email: manikonda433@gmail.com

\section{INTRODUCTION}

In the recent years, the demand is increased for multiband textile antennas because the WBAN is used for different wearable applications. It supports body to body and on-body communications. The wearable electronic devices on body can communicate using wearable antennas [1], [2].

The textile antennas are similar to Microstrip antenna but conductive and nonconductive materials of microstrip antenna are replaced with conductive (Shieldit, Zelt and Flectron) and non-conductive (jeans, felt and Dacron) fabrics, then it is called textile antenna. Textile antennas are easily embedded with garments. The textile antennas are comfortable, flexible, light weight to wear on human body and very low cost [3], [4].

EM waves are produced by textile antennas, when antennas are close to the human body, the body absorbs EM energy so the body tissues are more effected due to these waves. How much of EM energy is absorbed by tissues is calculated using Specific Absorption Rate (SAR)

$$
\mathrm{SAR}=\frac{\sigma \mathrm{E}_{i}^{2}}{\rho}
$$

$\sigma$-conductivity $(\mathrm{S} / \mathrm{m}), \mathrm{E}_{\mathrm{i}}$-Electric-field $(\mathrm{V} / \mathrm{m})$ and $\sigma-$ Density $\left(\mathrm{kg} / \mathrm{m}^{3}\right)$ of body tissue respectively. As for FCC standards, the averaged SAR value must be less than $1.6 \mathrm{~W} / \mathrm{kg}$ for $1 \mathrm{~g}$ of tissue and for European, the value must be less than $2 \mathrm{~W} / \mathrm{kg}$ for $10 \mathrm{~g}$ of tissue [5]. 
In [6], dual band monopole, wearable antenna is designed with EBG structure for SAR reduction. It covers GSM, ISM bands and EBG array is kept under the patch. In [7], the authors proposed felt cloth as substrate for double band wearable antenna resonant at the $2.45 \mathrm{GHz}$ and $5.5 \mathrm{GHz}$ with $3 \times 3 \mathrm{EBG}$ array. It improves gain and reduces the SAR. In [8], the Artificial Magnetic Conductor (AMC) is embedded with dual band slot dipole wearable antenna for SAR reduction with coaxially fed and AMC array is $4 \times 4$. In [9], authors used polyurethane foam for substrate and Shieldit textile for patch, ground. U-slot, slits on rectangular patch and shorting pins are used to design dual band textile antenna for ISM and HiperLAN bands. In [10], jeans cloth is substrate, two bands polygon shape textile antenna is implemented with circular slot, slits on patch and it resonates at $900 \mathrm{MHz}$ and $1800 \mathrm{MHz}$ bands. SAR values that are changed depends on thickness of tissues are observed. In [11], the authors proposed dual band wearable antenna for MIMO applications and multi band is achieved due to shorting wall of the patch, vias and felt is substrate. The SAR values are $0.056 \mathrm{~W} / \mathrm{kg}$ at $2.45 \mathrm{GHz}$ and $0.067 \mathrm{~W} / \mathrm{kg}$ at $5.5 \mathrm{GHz}$ and input power is $0.5 \mathrm{~W}$. In [12], the multi band G-shape monopole antenna with inverted L-shape parasitic elements is designed for computer applications. SAR is reduced to less than $1.4 \mathrm{~W} / \mathrm{Kg}$ over $1-\mathrm{g}$ of tissue and FR4 is substrate. In [13], the authors proposed mush-room CRLH-TL metamaterials structure inspired wearable antenna for SAR reduction at 2.4 and. $5.2 \mathrm{GHz}$ bands. It is fabricated with felt and Shieldit super fabrics. In [14], the circular ring, trimmed patch are combined and two feeds are used, one feed for circular ring and another feed for trimmed path, then the dual band is achieved. It is implemented with felt, shieldex fabrics and embedded into military berets for GPS L1 and ISM bands applications. In [15], LV logo shaped wearable antenna is designed using conductive textile and leather as a substrate .In LV logo antenna, dual band is achieved using longer thin and shorter thick arms of the antenna, it resonates at $2.45 \mathrm{GHz}$ and $4.5 \mathrm{GHz}$ bands. In [16], the authors created two arc slots and shorting pins on circular patch for dual band wearable antenna. The polydimethylsiloxane (PDMS) is used as nonconductive fabric and NCS95R-CR is a nylon ripstop fabric coated with nickel, copper and silver is used as conductive fabric for textile antenna. It is tuned to resonate at $2.45 \mathrm{GHz}$ and $5.8 \mathrm{GHz}$ bands. In [17], the first octagonal antenna with FR-4 substrate operated in single band, then the inverted E slot is created on first antenna and it is operated in the dual band. In [18], the authors designed antenna by two elements with different lengths with FR-4 material then the two bands achieved.it is fed by coplanar wave guide. In [19], the dual band antenna is implemented by circular patch with two stubs and it is fed by proximity coupled line.

This paper is arranged as, design, prototype of J-slot dual band textile antenna and proposed method is given in Section II. In section III, results and SAR analysis of proposed dual band textile antenna are shown. Finally, the conclusions are given in Section IV.

\section{TEXTILE ANTENNA DESIGN METHODOLOGY}

\subsection{Dual band J-slot Textile Antenna Design}

First, the dual band textile antenna is implemented with a J-slot on rectangular patch. The Figure 1 (a) shows the front view of dual band textile antenna and Figure1 (b) is the side view of antenna. It is combination of ground, substrate and patch. The J-slot is created on textile patch antenna. The size of the rectangular patch is $\mathrm{L}=38 \mathrm{~mm}$ and width is $\mathrm{W}=32 \mathrm{~mm}$. The dimensions of $\mathrm{J}$-slot are $\mathrm{L}_{1}=6 \mathrm{~mm}, \mathrm{~L}_{2}=16 \mathrm{~mm}$, $\mathrm{L}_{3}=22 \mathrm{~mm}$ and width is $1 \mathrm{~mm}$. The $\mathrm{L}_{\mathrm{s}}=71 \mathrm{~mm}, \mathrm{~W}_{\mathrm{s}}=68 \mathrm{~mm}, \mathrm{~h}=2.4 \mathrm{~mm}$ are length, width and height of substrate. The Jeans fabric is used as substrate with dielectric constant 1.67 , loss tangent 0.023 . The size of the ground plane is $71 \mathrm{~mm} \times 68 \mathrm{~mm}$. The $\mathrm{L}_{\mathrm{f}}=28 \mathrm{~mm}, \mathrm{~W}_{\mathrm{f}}=2 \mathrm{~mm}$ are length and width of Microstrip feed line.

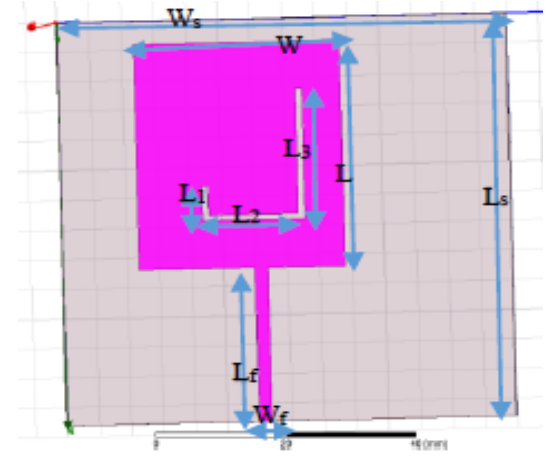

(a)

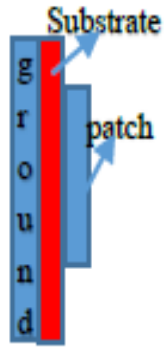

(b)

Figure 1. Schematic of proposed Textile antenna, (a) Front, (b) Side view 


\subsection{J-slot EBG structure}

The proposed square shape EBG cell with J-slot is shown in Figure 2. The J-slot is created on square EBG cell for dual band operation of cell. The length and width of $E B G$ cell are equal i.e. $L_{e}=W_{e}=32 \mathrm{~mm}$. The parameters of J-slot are $\mathrm{L}_{\mathrm{s} 1}=5 \mathrm{~mm}, \mathrm{~L}_{\mathrm{s} 2}=15 \mathrm{~mm}, \mathrm{~L}_{\mathrm{s} 3}=10 \mathrm{~mm}$ and width is $1 \mathrm{~mm}$. Here, jeans cloth used as a substrate. The gap between adjacent cells are $0.6 \mathrm{~mm}$, then the periodicity of J-slot EBG cell is $32.6 \mathrm{~mm}$ along the Y-direction. The Floquet port is used for excitation of periodic J-slot EBG cell.

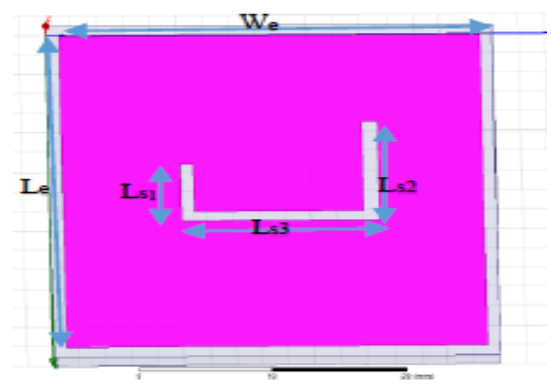

Figure 2. Geometry of Proposed J-slot EBG cell

The fabricated J-slot textile antenna without EBG is shown in Figure 3(a). The fabricated J-slot EBG structure is used as a superstrate of the J-slot Textile antenna is shown in figure 3(b) and it is positioned 0.8 $\mathrm{mm}$ height from the patch of J-slot Textile antenna. The layers of textile antenna are manually cut by scissor and layers are stitched.

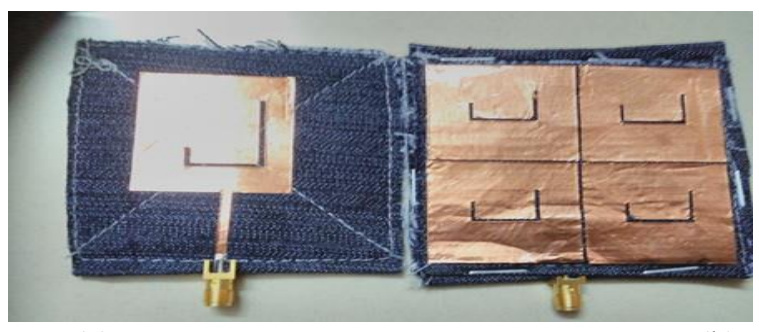

(a)

(b)

Figure 3. Prototype of Proposed J-slot textile antenna front view (a) without EBG (b) with J-slot EBG structure

\subsection{J-slot Textile Antenna with J-slot EBG Structure}

The Figure 4 (a) shows the J-slot textile antenna with J-slot EBG structure on phantom model of human body and Figure 4 (b) is side view of Textile antenna. The dimensions of textile antenna are same for without and with human body. The J-slot EBG structure is used as superstrate for textile antenna and $\mathrm{d}_{2}=0.8$ $\mathrm{mm}$ is the distance between the J-slot patch and J-slot EBG array. The size of the J-slot EBG array is $2 \times 2$. The air gap between Phantom model and Ground plane of J-slot Textile antenna is $\mathrm{d}_{1}=2 \mathrm{~mm}$.

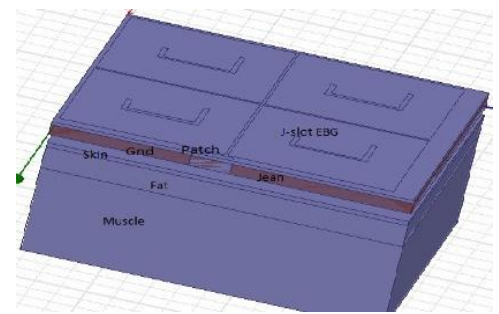

(a)

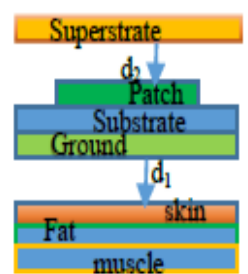

(b)

Figure 4. Simulated J-slot Textile antenna with J-slot EBG array, (a) Front View, (b) Side View 


\section{RESULTS AND DISCUSSION}

All the Results are simulated using Ansoft HFSS software for the proposed Dual Band J-slot Textile antenna. The Figure 5 shows reflection phase of dual band J-slot EBG cell. The reflection phase is nearly $0^{\circ}$ at $2.43 \mathrm{GHz}$ and at $5.42 \mathrm{GHz}$, so the J-slot EBG cell operates in dual band.

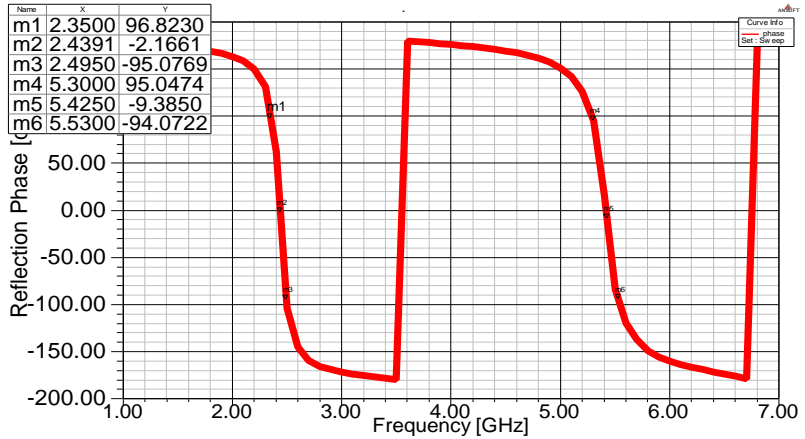

Figure 5. The Reflection Phase of J-slot EBG structure

The Figure 6 shows the J-slot dual band textile antenna without EBG structure resonates at $2.4 \mathrm{GHz}$, with Reflection coefficient of $-11.7 \mathrm{~dB}$, impedance bandwidth is $170 \mathrm{MHz}$ and at $5.4 \mathrm{GHz}$ with Reflection coefficient of $-22.1 \mathrm{~dB}$, impedance bandwidth is $320 \mathrm{MHz}$.

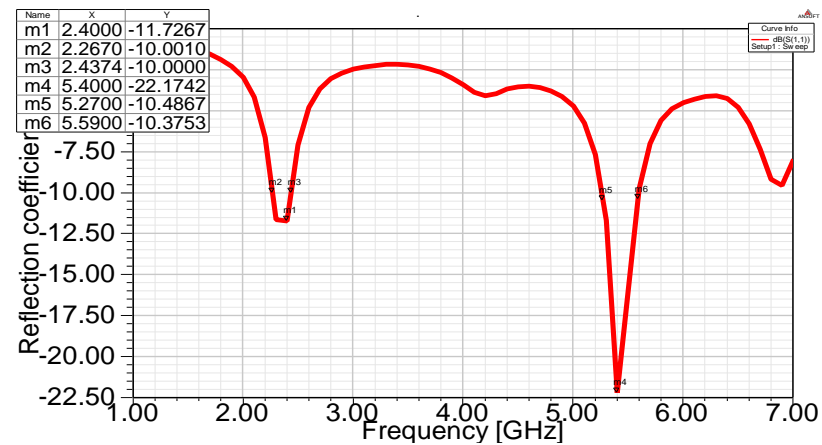

Figure 6. The J-slot dual band Textile Antenna without EBG array and without Phantom Model

The Reflection coefficient of the J-slot textile antenna without EBG structure on Phantom model is shown in Figure 7. The dual band textile antenna resonates at $2.2 \mathrm{GHz}$ with Reflection coefficient of -15.4 $\mathrm{dB}$, impedance bandwidth is $240 \mathrm{MHz}$ and another band resonates at $6 \mathrm{GHz}$ with Reflection coefficient of $-16.9 \mathrm{~dB}$, impedance bandwidth is $300 \mathrm{MHz}$. Here, $-10 \mathrm{~dB}$ is the reference line for calculation of Impedance Bandwidth. The frequency shift is occurred due to phantom model of human body.

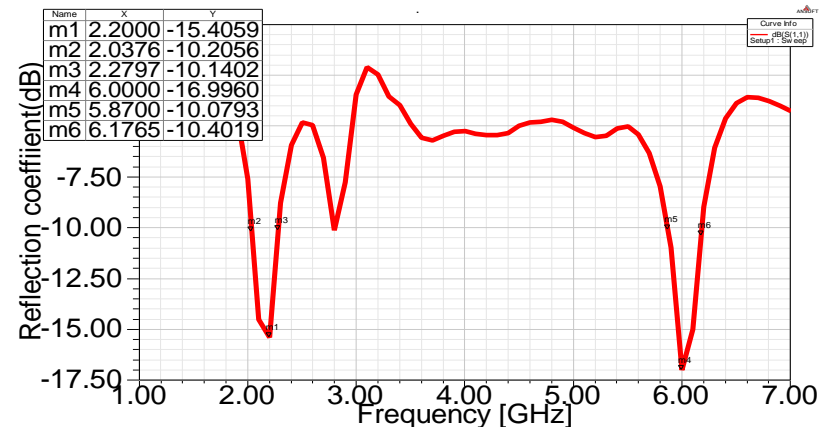

Figure 7. The J-slot Textile Antenna without EBG on Phantom Model 
The Figure 8 shows the measured Reflection coefficient of dual band J-slot textile antenna without J-slot EBG array on human body. It resonates at $2.46 \mathrm{GHz}, 6.39 \mathrm{GHz}$ with Reflection coefficients $-11.9 \mathrm{~dB}$, $-18 \mathrm{~dB}$ respectively. Here, the frequency shift is occurred due to textile Antenna operates near to human body.

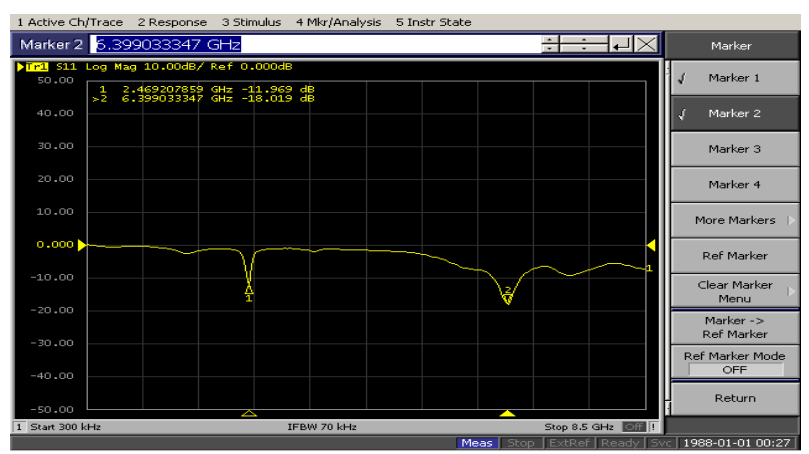

Figure 8 . The dual band textile Antenna without EBG on human body

The Figure 9 (a) shows the simulated Reflection coefficient of dual band J-slot textile antenna with J-slot EBG structure as superstrate. The lower band resonates at $2.4 \mathrm{GHz}$ with Reflection coefficient of -15.8 $\mathrm{dB}$, impedance band width is $160 \mathrm{MHz}(2.3 \mathrm{GHz}$ to $2.46 \mathrm{GHz})$ and second band resonates at $5.5 \mathrm{GHz}$ with Reflection coefficient of $-26.8 \mathrm{~dB}$, impedance bandwidth is $320 \mathrm{MHz}(5.32 \mathrm{GHz}$ to $5.64 \mathrm{GHz})$. The Figure 9 (b) shows the measured Reflection coefficient of dual band J-slot textile antenna with EBG array as superstrate on human body. The dual bands of antenna are at $2.17 \mathrm{GHz}, 5.47 \mathrm{GHz}$ with Reflection coefficients of $-22.9 \mathrm{~dB}, 25.3 \mathrm{~dB}$ respectively. The lower frequency band shift is occurred due to gap between layers of antenna.

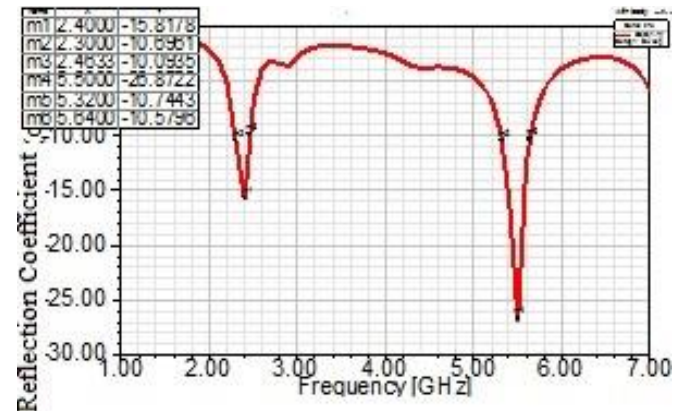

(a)

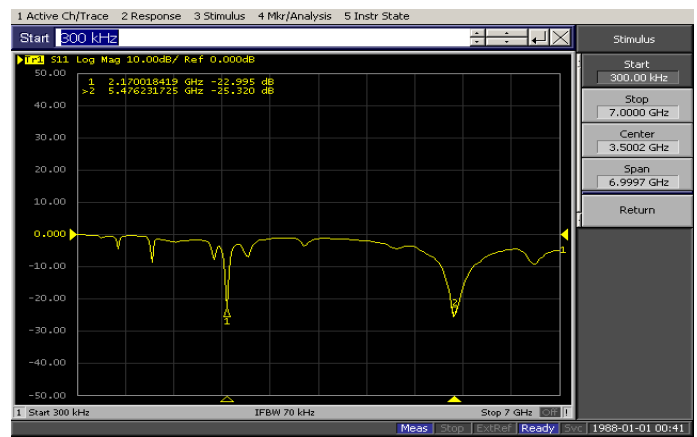

(b)

Figure 9. The J-slot Textile Antenna with J-slot EBG on phantom model

The Figure 10(a) shows the simulated VSWR of the dual band J-slot textile antenna with J-slot EBG structure as superstrate on phantom model. The VSWR value is 1.63 at $2.4 \mathrm{GHz}$ and 1.21 at $5.4 \mathrm{GHz}$. Both VSWR values are less than 2 and VSWR $=2$ is a reference line. The Figure 10(b) shows the measured VSWR of the dual band Textile antenna with J-slot EBG as a superstrate and antenna is positioned on the human body. The measured VSWR is $1.07,1.11$ at $2.17 \mathrm{GHz}, 5.47 \mathrm{GHz}$ respectively.

The Figure 11 shows the gain of the Dual Band J-slot textile antenna without EBG array on phantom model. The gain of the J-slot textile antenna at $2.4 \mathrm{GHz}$ is $-3.66 \mathrm{~dB}$ and at $5.4 \mathrm{GHz}$ is $1.18 \mathrm{~dB}$. 


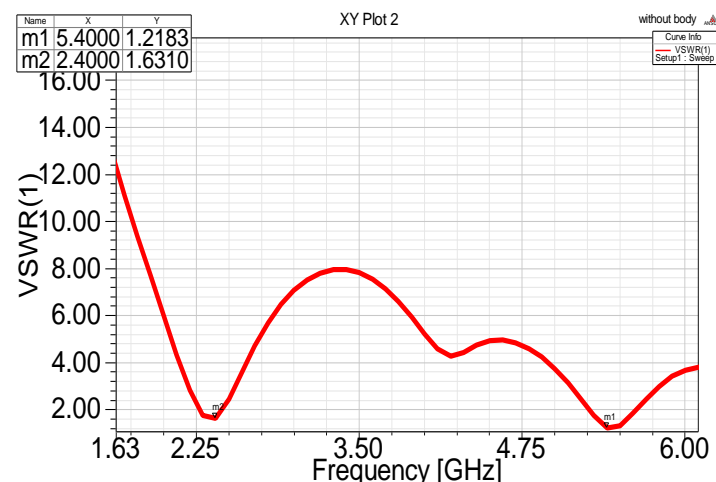

(a)

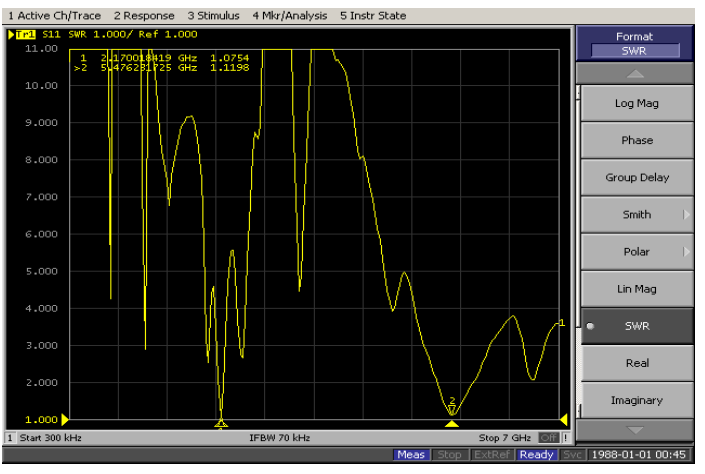

(b)

Figure 10. VSWR of textile antenna with EBG on phantom model

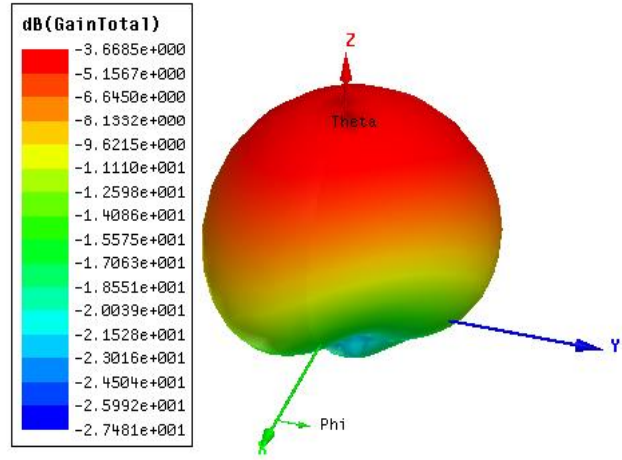

(a)
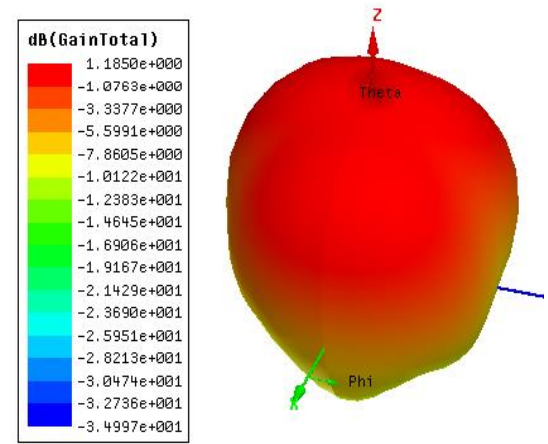

(b)

Figure 11. Gain of J-slot Textile antenna without EBG structure on phantom model of human body (a) 2.4 $\mathrm{GHz}$, (b) $5.4 \mathrm{GHz}$

The Gain of the dual band J-slot textile antenna with J-slot EBG array on phantom model is shown in Figure 12. The gain of the dual band antenna is $2.44 \mathrm{~dB}$ at $2.4 \mathrm{GHz}$ and $5.03 \mathrm{~dB}$ at $5.4 \mathrm{GHz}$. The gain of the textile antenna is improved due to J-slot EBG array. The EM waves are reflected between J-slot EBG structure and ground, then the aperture size of antenna is increased and surface waves are cancelled, so gain is enhanced and back radiation is reduced.

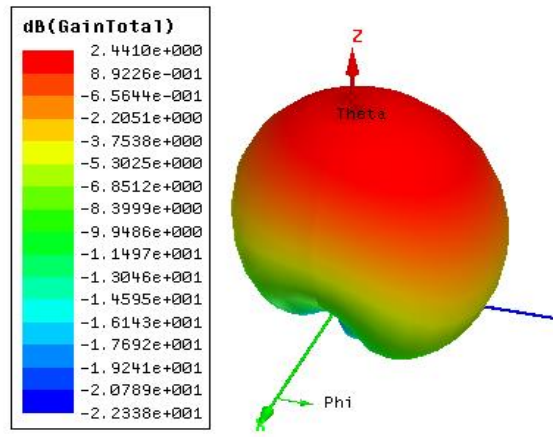

(a)
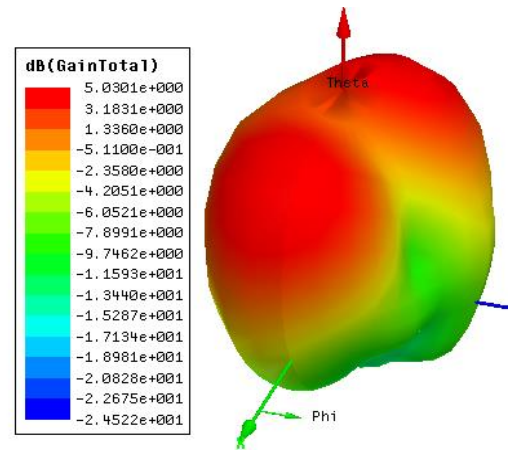

(b)

Figure 12. Gain of J-slot Textile antenna with EBG structure on phantom model of human body (a) $2.4 \mathrm{GHz}$, (b) $5.4 \mathrm{GHz}$ 


\subsection{Analysis of SAR}

The three layered rectangular phantom model of human body is created with Skin, Fat and Muscle [20] to simulate the SAR value of proposed textile antenna. The dimensions of the rectangular phantom model is $71 \times 68 \times 14 \mathrm{~mm}^{3}$. The dielectric properties and thickness of tissues for the human phantom model are given in Table 1 .

Table 1. Dielectric Properties of Tissues for Human Body

\begin{tabular}{ccccc}
\hline Parameters & Frequency & Skin & Fat & Muscle \\
\hline Conductivity & $2.4 \mathrm{GHz}$ & 1.561 & 0.102 & 1.705 \\
$(\mathrm{~S} / \mathrm{m})$ & $5.4 \mathrm{GHz}$ & 3.951 & 0.267 & 4.493 \\
Relative & $2.4 \mathrm{GHz}$ & 42.923 & 5.285 & 52.791 \\
permittivity & $5.4 \mathrm{GHz}$ & 39.118 & 4.991 & 49.015 \\
Loss Tangent & $2.4 \mathrm{GHz}$ & 0.272 & 0.145 & 0.241 \\
Thickness(mm) & $5.4 \mathrm{GHz}$ & 0.336 & 0.178 & 0.305 \\
\hline
\end{tabular}

The averaged SAR value for dual band J-slot textile antenna without EBG array at $2.4 \mathrm{GHz}$ is 2.76 $\mathrm{W} / \mathrm{kg}$ and at $5.4 \mathrm{GHz}$ is $2.90 \mathrm{~W} / \mathrm{kg}$ for $0.5 \mathrm{~W}$ of input power are shown in Figure 13(a) and 13(b) respectively and it must be less than $2 \mathrm{~W} / \mathrm{kg}$ over $10 \mathrm{~g}$ of tissues.

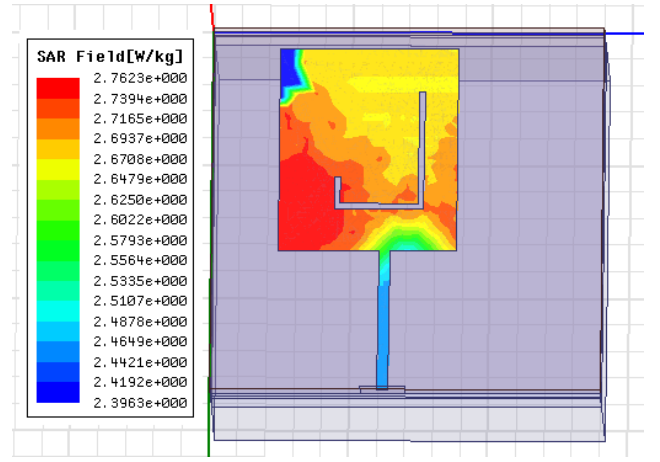

(a)

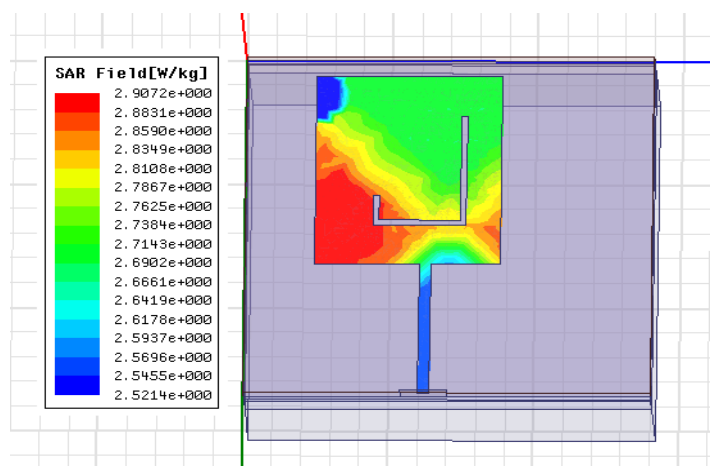

(b)

Figure 13. SAR value of dual band textile antenna without EBG on body, (a) $2.4 \mathrm{GHz}$, (b) $5.4 \mathrm{GHz}$

The averaged SAR value of proposed dual band J-slot textile antenna with J-slot EBG array on phantom model of human body is shown in Figure 14. The averaged SAR value is $0.85 \mathrm{~W} / \mathrm{Kg}$ at $2.4 \mathrm{GHz}$ and $1.83 \mathrm{~W} / \mathrm{kg}$ at $5.4 \mathrm{GHz}$ for $10 \mathrm{~g}$ of tissue. The SAR value is reduced because back lobe is reduced due to J-slot EBG structure. It is less than the value specified by

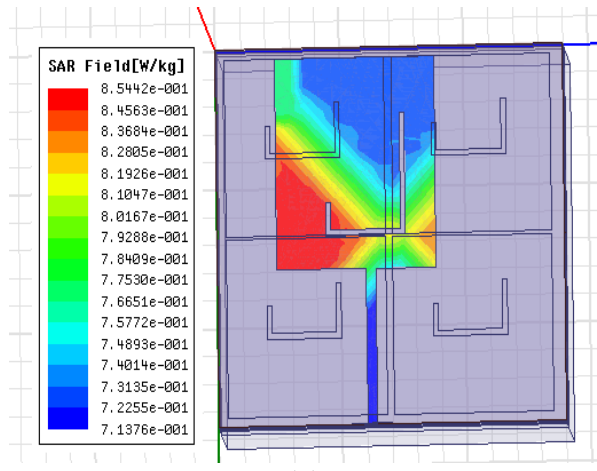

(a)

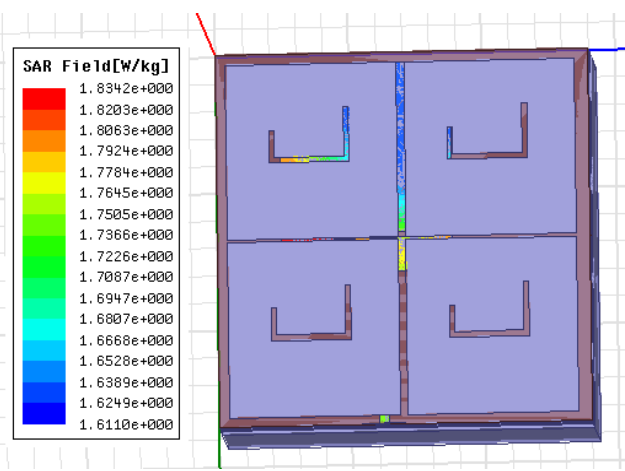

(b)

Figure 14. SAR value of dual band textile antenna with J-slot EBG structure on body, (a) $2.4 \mathrm{GHz}$, (b) $5.4 \mathrm{GHz}$ 


\section{CONCLUSION}

The proposed Textile antenna with J-slot EBG structure shows the better Radiation characteristics compare with the without EBG structure. The SAR values are reduced from $2.76 \mathrm{~W} / \mathrm{kg}$ to $0.85 \mathrm{~W} / \mathrm{kg}$ at 2.4 $\mathrm{GHz}$, from $2.9 \mathrm{~W} / \mathrm{kg}$ to $1.83 \mathrm{~W} / \mathrm{kg}$ at $5.4 \mathrm{GHz}$ over $10 \mathrm{~g}$ of tissue and gain is enhanced from $-3.66 \mathrm{~dB}$ to 2.44 $\mathrm{dB}$ at $2.4 \mathrm{GHz}$, from $1.18 \mathrm{~dB}$ to $5.03 \mathrm{~dB}$ at $5.4 \mathrm{GHz}$ using dual band J-slot textile antenna with J-slot EBG array as a superstrate on phantom model of human body. It is used for WBAN applications. The prototype dual band textile antenna resonates at $2.17 \mathrm{GHz}$ and $5.47 \mathrm{GHz}$.

\section{REFERENCES}

[1] Mehmet R.Yuce and Jamil.Y.khan, "wireless body area networks technology, implementation and applications, "Pan Stanford publishing, 2011.

[2] N. A. Elias, N. A. Samsuri, M. K. A. Rahim, C. J. Panagamuwa, and W. Whittow," SAR Levels for Irradiation by a Crumpled $900 \mathrm{MHz}$ Flexible Diamond Dipole," International Journal of Electrical and Computer Engineering (IJECE) Vol. 7, No. 3, June 2017, pp. 1546 1553.

[3] Ramesh Manikonda, Rajya Lakshmi Valluri and Mallikarjuna Rao Prudhivi,” Specific Absorption Rate Reduction Using EBG Structure as Superstrate for Textile Antenna," ARPN Journal of Engineering and Applied Sciences, Vol. 13, No. 10, Pg.3495-3501, MAY 2018.

[4] S. Sankaralingam and Bhaskar Gupta, "Determination of Dielectric Constant of Fabric Materials and Their use as Substrates for Design and Development of Antennas for Wearable Applications," IEEE Transactions on Instrumentation and Measurement, vol. 59, NO. 12, DEC 2010.

[5] IEEE C95.1-2005 "IEEE Standard for Safety Levels with Respect to Human Exposure to Radio Frequency Electromagnetic Fields, $3 \mathrm{kHz}$ to $300 \mathrm{GHz}$," IEEE International Committee on Electromagnetic Safety (SCC39), IEEE-SA Standards Board, 3 October 2005.

[6] Sangeetha. V, E.F. Sundarsingh, Malathi.K," Dual band EBG Integrated Monopole Antenna Deploying Fractal Geometry for Wearable applications," IEEE Antenna and Wireless Propagation Letters, Vol.14, 2015, pg249-252.

[7] Shaozhen Zhu, Richard Langley," Dual band wearable Textile antenna on an EBG substrate," IEEE transaction on antennas and propagation, vol.57, no.4, Apr, 2009, pg.926-935.

[8] Sen yan, ping jack soh, G.A.E. Vandenbosch," Low profile dual band textile antenna with artificial magnetic conductor plane, "IEEE Transactions on antenna and propagation, vol.62, no.12, Dec, 2014, pg.6487-6490.

[9] N.H.M.Rais, Ping Jack soh, M.FA.Malek and G.A.E.Vanenbosch," dual band suspended-plate wearable textile antenna," IEEE Antennas and wireless propagation letters, vol.12, 2013, pg.583-586.

[10] E.F.Sundarsingh, S. Velan, Malathi. K,A.K.Sarma, C. Raviteja and M.G.N.Alsath,"polygon shaped slotted dual band antenna for wearable applications," IEEE Antennas and Wireless propagation Letters, vol 13,2014, pg.611-614.

[11] Sen Yan, Ping Jack Soh, Sen, and Guy A. E. Vandenbosch," Dual-Band Textile MIMO Antenna Based on Substrate-Integrated Waveguide (SIW) Technology," IEEE Transactions on Antennas and Propagation, Vol. 63, NO. 11, NOV, 2015.

[12] Jui-Han Lu and Yi-Shiang Wang," Planar Small-Size Eight-Band LTE/WWAN Monopole Antenna for Tablet Computers," IEEE Transactions on Antennas and Propagation, vol.62, No.8, Aug 2014, Pg.4372-4377.

[13] Sen Yan, Ping Jack Soh, and Guy A. E. Vandenbosch," Compact All-Textile Dual-Band Antenna Loaded with Metamaterials-Inspired Structure," IEEE Antennas and Wireless Propagation Letters, Vol. 14, 2015, pg. 1486-1489.

[14] Heejae Lee, Jinpil Tak, and Jaehoon Choi, ” Wearable Antenna Integrated into Military Berets for Indoor/Outdoor Positioning System," IEEE Antennas and Wireless Propagation Letters, Vol. 16, 2017, pg.1919-1922.

[15] Jinpil Tak, and Jaehoon Choi,"An All-Textile Louis Vuitton Logo Antenna," IEEE Antennas and Wireless Propagation Letters, Vol. 14, 2015, pg.1211-1214.

[16] Roy B. V. B. Simorangkir, Yang Yang,Ladislau Matekovits and Karu P. Esselle,” Dual-Band Dual-Mode Textile Antenna on PDMS Substrate for Body-Centric Communications," IEEE Antennas and Wireless Propagation Letters, Vol. 16, 2017, pg.677-680.

[17] Mohamed Tarbouch, Abdelkebir El Amri and Hanae Terchoune," Design, Realization and Measurements of Compact Dual-band CPW-fed Patch Antenna for 2.45/5.80 GHz RFID Applications," International Journal of Electrical and Computer Engineering (IJECE), Vol. 8, No. 1, February 2018, pp. 172-178.

[18] Ahmed El Hamraoui, EL Hassane Abdelmounim, Jamal Zbitou, Hamid Bennis, and Mohamed Latrach," A New Design of a CPW-Fed Dual-Band Monopole Antenna for RFID Readers," International Journal of Electrical and Computer Engineering (IJECE), Vol. 8, No. 2, April 2018, pp. 1040 1047.

[19] A. H. Majeed and K. H. Sayidmarie ," Extended-Bandwidth Microstrip Circular Patch Antenna for Dual Band Applications," International Journal of Electrical and Computer Engineering (IJECE), Vol. 8, No. 2, April 2018, pp. 1056 1066.

[20] Gabriel C. 1996. Compilation of the Dielectric Properties of Body Tissues at RF and Microwave Frequencies. Brooks Air Force Technical Report, AL/OE-TR-1996-0037: www. iremf.ifac.cnr.it/tissprop/ 


\section{BIOGRAPHIES OF AUTHORS}
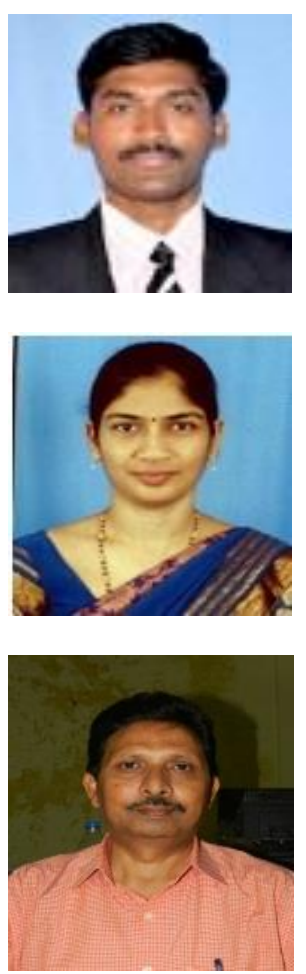

Ramesh MANIKONDA. He received his M.Tech. Degree from Andhra University in 2006 and pursuing Ph.D. from Andhra University. He is working as an Assistant Professor in GITAM University, Visakhapatnam. His research interests include Microstrip Antenna, wearable antenna and wireless communication. E-mail id: manikonda433@gmail.com

RajyaLakshmi VALLURI. She is working as Professor in ANITS college of Engineering, Visakhapatnam. She received her M. Tech and Ph.D. Degree from Andhra University. Her research interests include Wearable Antenna, Antenna Array and Microstrip Antenna.

Mallikarjuna Rao PRUDHIVI. He took his M.E. Degree in ECE from Andhra University in 1985 and later obtained his Ph.D. Degree in 1998. He received best Ph.D. award from Andhra University in 1999.He joined as Assistant Professor in the Department of Electronics and Communication Engineering, Andhra University in 1990. Subsequently he became Professor in 2002. His research interests include Microstrip Antenna, Antenna array and wireless communication. 